\title{
Reliability Analysis on CEDI Water Treatment System based on GO Methodology
}

\author{
Xin $\mathrm{Guo}^{1,}$, Ning Zhao ${ }^{1, b}$, Chunyuan Jing ${ }^{1, c}, \mathrm{Jin}_{\mathrm{Li}}^{1, \mathrm{~d}}$, Min Bai ${ }^{1, \mathrm{e}}$ \\ ${ }^{1}$ Northwest Institute of Nuclear Technology, Xi'an, 710024, China

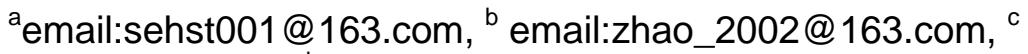 \\ email:jingcy59582@sohu.com, demail:lijin8r7232@163.com, e email:bai3434h@163.com
}

Keywords: GO methodology; reliability; CEDI system

\begin{abstract}
The reliability of CEDI water treatment system was analyzed. The failure rate and mean failure-free operation time of the system were demonstrated, according to the GO diagram of CEDI system and GO methodology calculating formula, and the conclusion was coincident with actual working. Furthermore, the importance of failure rates of different components was analyzed, and the measures to improve the reliability of the system were also discussed, which were meaningful to the usage and maintenance of the CEDI water treatment system. In addition, this method can also be applied widely to the analysis of the reliability and security of industrial sectors.
\end{abstract}

\section{Introduction}

The GO methodology is a kind of success oriented system probability analysis technology. It was originally put forward by the American Kaman science company in the mid - 1960 - s, and was mainly used for missile systems and in nuclear security fields, to solve the problem of the reliability of complex systems. After long time of research and development, the function of the GO methodology is gradually improved, and the quantitative calculation formulas of the operator and general program in the repairable system are derived[1].

The basic idea of GO methodology is translating the system structure, flow chart and engineering drawing into the GO figure according to certain rules directly. Elements of the GO methodology directly represent the logical relationship between the components and parts[2]. According to the GO diagram, using GO operation rules to complete the GO calculation can complete the system reliability analysis. There are many components in a CEDI water treatment system[3], therefore when using the GO methodology to analyze it, the GO figure has compact structure, small volume, and is easy to implement.

Based on estimating the system failure rate and mean time to repair of different components of CEDI Water treatment system, the failure rate, mean failure-free operation time, mean probability of working and reliability index are calculated by GO methodology, and the importance of individual parts is analyzed,. Finally, the measures to improve the CEDI water treatment system reliability are discussed.

\section{The GO methodology in the application of CEDI systems}

The reliability of the system characteristics.

CEDI water treatment system is an alternating system under normal working state and shutdown maintenance state. System malfunction and complete maintenance time both obey exponential distribution [4]. After reaching stable reliability, the system characteristic parameters include the system failure rate $\lambda$, system repair rate $\mu$, system mean probability of working $p$, mean free error time $M I B F=1 / \lambda$, mean time to repair $M T T R=1 / \mu$, average life-span $M C T=M T B T+M T T R$, and the failure rate per unit time $f=\lambda \mu /(\lambda+\mu)$.

The GO methodology of quantitative calculation methodology.

GO methodology defines the 17 types of standard operator, as shown in figure1. Diagram text corresponds to the operator name; the number in the operator graphic represents the digital type; 
arrow $S$ represents the input signal; and the arrow $R$ represents the output signal [4].

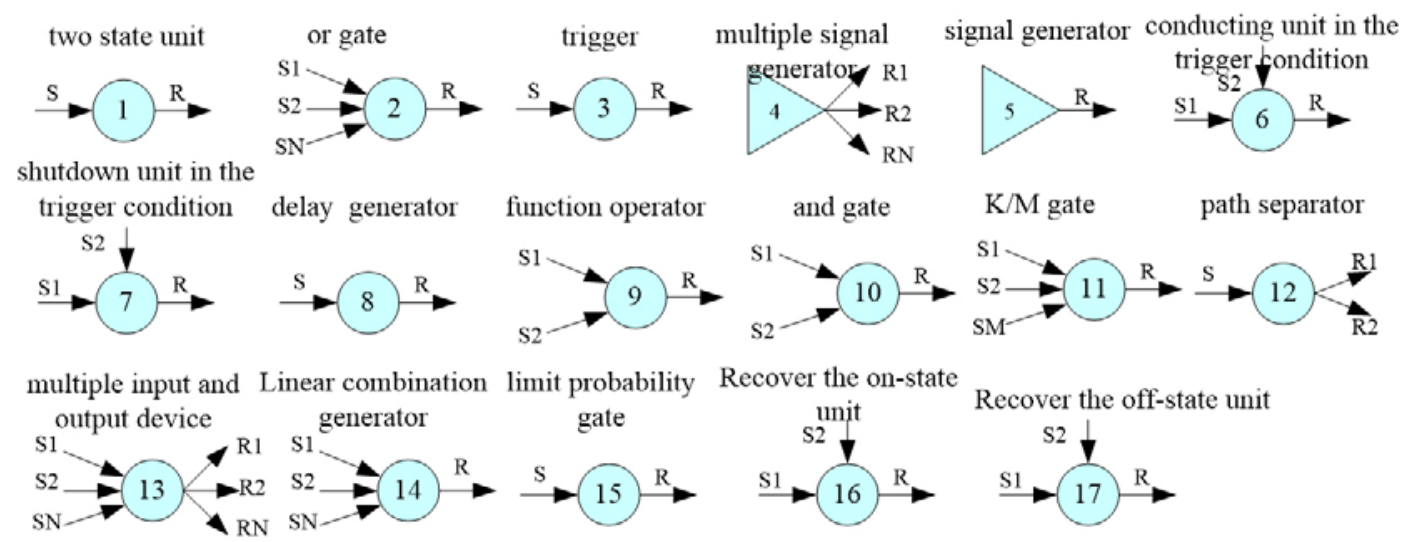

Fig.1 Operator types of GO methodology

Operator input signal to the success of state probability, equivalent failure rate and equivalent maintenance rate are respectively denoted by $\boldsymbol{P}_{s}, \lambda_{s}$ and $\boldsymbol{\mu}_{s}$. The success of the operator itself state probability, failure rate and repair rate are respectively denoted by $\boldsymbol{P}_{\boldsymbol{c}}, \boldsymbol{\lambda}_{\boldsymbol{c}}$ and $\boldsymbol{\mu}_{\boldsymbol{c}}$. Operator, equivalent failure rate and the equivalent output signal success state probability maintenance rate are respectively denoted by $\boldsymbol{P}_{\boldsymbol{R}}, \boldsymbol{\lambda}_{\boldsymbol{R}}$ and $\boldsymbol{\mu}_{R}$ [5].

CEDI water treatment system with the GO methodology involves four operators and its computation formula is as follows.

1) type 1 state of two units

The operator can be simulated with an input signal and an output signal of the unit., The unit itself has two states. During the normal work of the unit, the signal can pass; when the unit is in a state of breakdown maintenance, the signal can't pass. The calculation formula is:

$$
P_{R}=P_{S} \bullet P_{C}, \quad \lambda_{R}=\lambda_{S}+\lambda_{C}, \mu_{R}=\lambda_{R} \bullet \frac{P_{R}}{1-P_{R}}=\lambda_{R} /\left(\frac{\lambda_{S}}{\mu_{S}}+\frac{\lambda_{C}}{\mu_{C}}\right)
$$

2) type 5 signal generator

The operator has no input, and only one output signal. It works as the input signal of the system, therefore it is the system input operator. The data for the operators are the data of the output signal. The calculation formula is:

$$
P_{R}=P_{C}, \lambda_{R}=\lambda_{C}, \mu_{R}=\mu_{C}
$$

3) type 6 conducting unit in the trigger conductions

The operator has two input signals, the main conditions and input signals. When the condition input signal is successfully input, the unit is successfully conducted. When the main input signal is normally input, the output signal can be normally output. Therefor the two input signal and the unit on the reliability of the logical relationship is in series. The type 6 operators can represent system, there is a certain condition in addition to the main pathways of parts. Calculation formula is:

$$
P_{R}=P_{S 1} \bullet P_{S 2} \bullet P_{C}, \quad \lambda_{R}=\lambda_{S 1}+\lambda_{S 2}+\lambda_{C}, \quad \mu_{R}=\lambda_{R} \bullet \frac{P_{R}}{1-P_{R}}=\lambda_{R} /\left(\frac{\lambda_{S 1}}{\mu_{S 1}}+\frac{\lambda_{S 2}}{\mu_{S 2}}+\frac{\lambda_{C}}{\mu_{C}}\right)
$$

4) type $11 \mathrm{M} \mathrm{K}$ gate

This operator is a logical operators, do not need probability data, used to simulate $\mathrm{M}$ of $\mathrm{K} \mathrm{a}$ signal of the "vote" logical relationship, to get the output signal. Calculation formula is:

$$
P_{R}=\sum_{i=0}^{M-K} P_{i} / \sum_{i=0}^{I} P_{i}, \quad \lambda_{R}=P_{M-K} \bullet a_{M-K+1} / \sum_{i=0}^{M-K} P_{i}, \quad \mu_{R}=P_{M-K+1} \bullet b_{M-K+1} / \sum_{i=M-K+1}^{I} P_{i}
$$

\section{GO diagram of CEDI system}

\section{System analysis.}

CEDI water treatment system are processed by the pretreatment system, two-stage RO system, CEDI module, cleaning system and so on several parts[6], containing water production and back 
washing system structure diagram as show in figure 1.

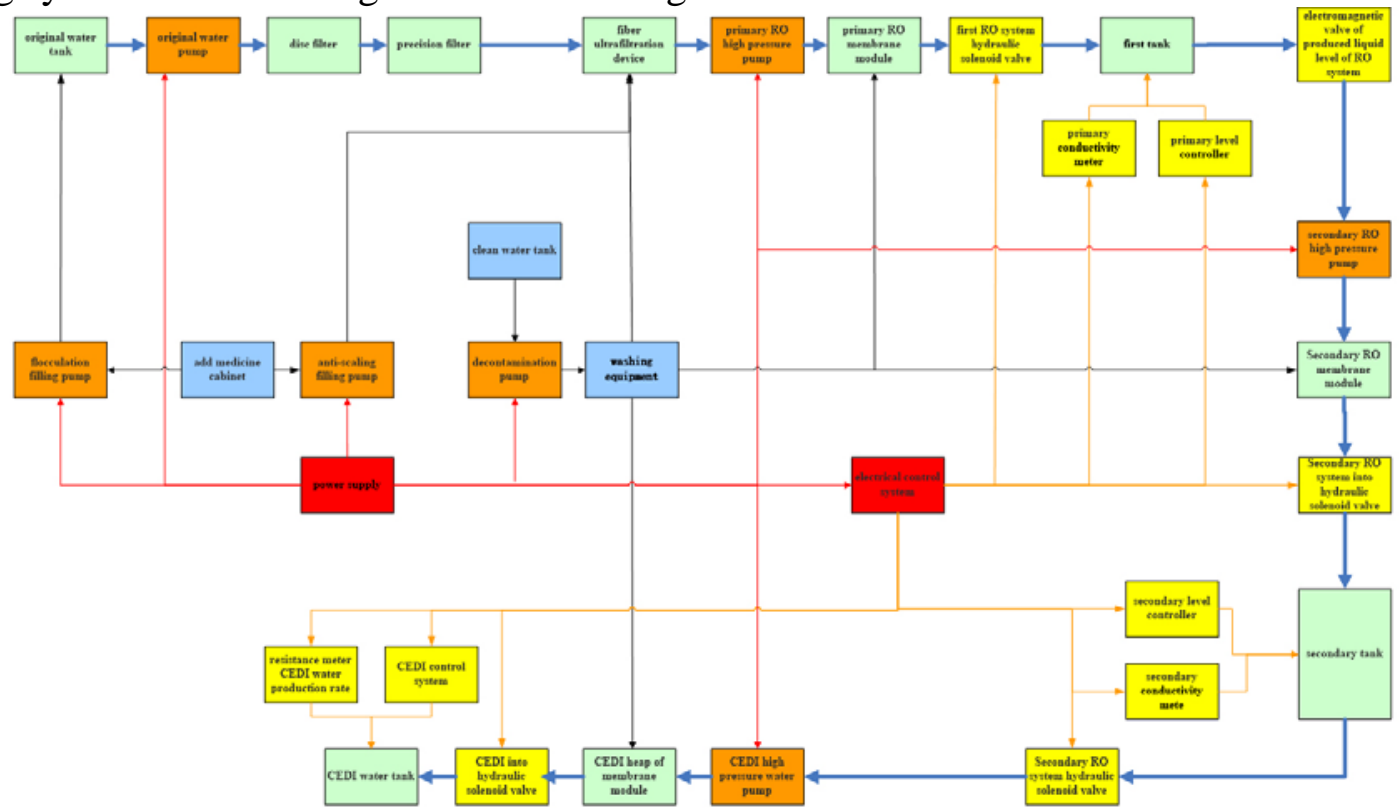

Fig.2 Structure diagram of CEDI system

\section{Establish GO diagram.}

Power supply, adding medicine cabinet and the original water tank is input device, represented by the signal generator with type 5 . The 13 units such as the total control system with only one input and one output, using state of two type 1 unit. The 13 units such as high-pressure pump, solenoid valve which has a primary input signal and the signal, a condition with type 6 signal conduction component. Primary and secondary water tank, and the CEDI tank 3 units with $11 \mathrm{M}$ take $\mathrm{K}$ type door original expressed.

After connection of signal flow for operator and signal flow number [7][8], complete system GO diagram as shown in figure2. There're a total of 32 operators, and the figure 32 flow signal, number. 32 operators output signal flow is the output of the system signal flow, its reliability characteristics represent the reliability characteristic of CEDI water treatment systems.
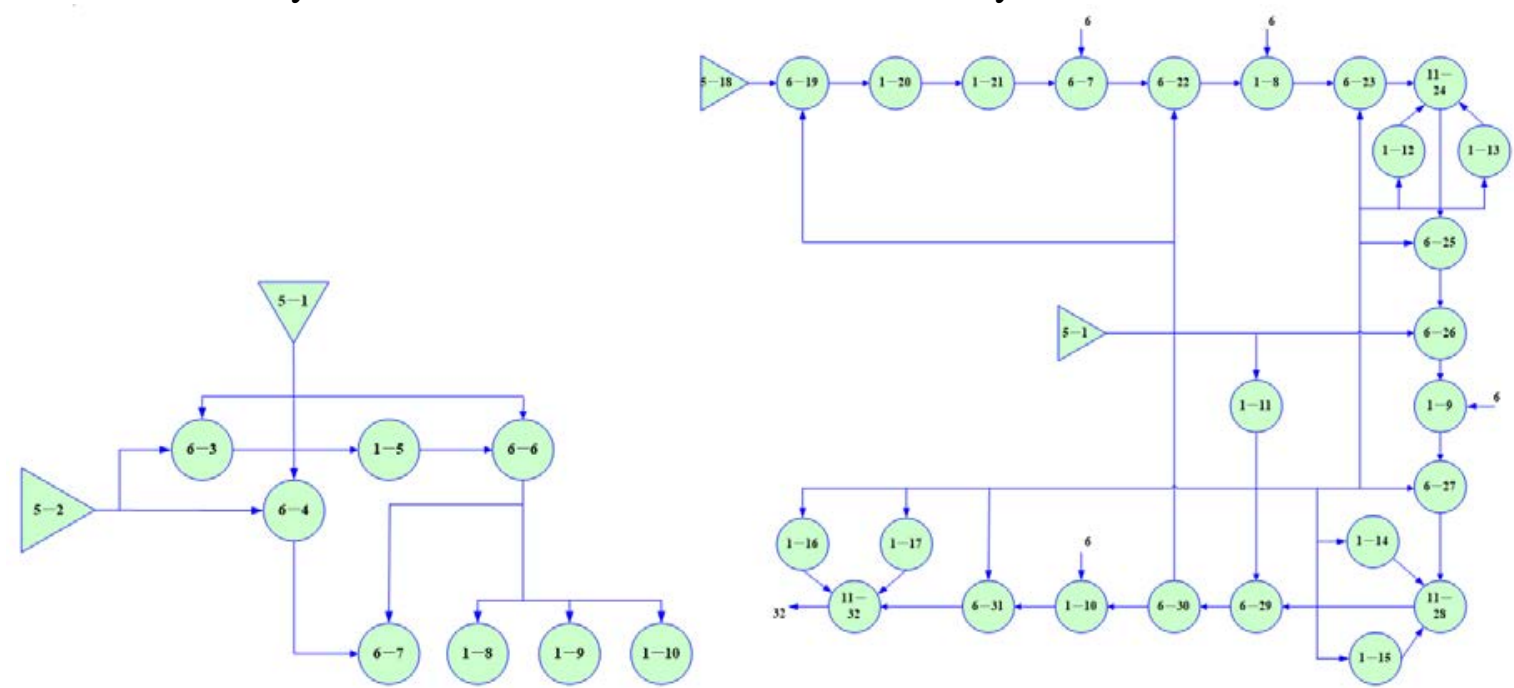

Fig.3 GO diagram of CEDI system (figures represent "type - No." and they are listed in Table 1

\section{The reliability analysis of CEDI system}

Reliability index of CEDI system.

After establishing GO diagram of CEDI water treatment systems, calling the each unit module reliability data in table1 (empirical value), and applying the calculation formula to calculate the GO 
methodology, the system reliability index is obtained, as shown in table2, $\boldsymbol{a}$ represent "year" in the table.

Table 1 Initial unit data of CEDI system

\begin{tabular}{|c|c|c|c|c|c|c|c|}
\hline $\begin{array}{l}\text { Type- } \\
\text { No. }\end{array}$ & unit name & $\begin{array}{c}\text { failure } \\
\text { rate/ } \\
\mathrm{a}^{-1} \\
\end{array}$ & $\begin{array}{l}\text { repair } \\
\text { time/h }\end{array}$ & $\begin{array}{l}\text { Type- } \\
\text { No. }\end{array}$ & unit name & $\begin{array}{c}\text { failure } \\
\text { rate/ } \\
\mathrm{a}^{-1} \\
\end{array}$ & $\begin{array}{l}\text { repair } \\
\text { time/h }\end{array}$ \\
\hline $5-1$ & power supply & 0.2 & 4 & $1-17$ & $\begin{array}{l}\text { CEDI into hydraulic } \\
\text { solenoid valve }\end{array}$ & 0.7 & 7 \\
\hline $5-2$ & add medicine cabinet & 0.1 & 2 & $5-18$ & original water tank & 0.1 & 2 \\
\hline $6-3$ & $\begin{array}{l}\text { flocculation filling } \\
\text { pump }\end{array}$ & 0.4 & 2 & $6-19$ & original water pump & 0.4 & 2 \\
\hline $6-4$ & anti-scaling filling pump & 0.4 & 2 & $1-20$ & disc filter & 0.3 & 4 \\
\hline $1-5$ & clean water tank & 0.1 & 2 & $1-21$ & precision filter & 0.5 & 5 \\
\hline $6-6$ & decontamination pump & 0.4 & 2 & $6-22$ & $\begin{array}{l}\text { primary RO high } \\
\text { pressure pump }\end{array}$ & 0.4 & 2 \\
\hline $6-7$ & $\begin{array}{c}\text { fiber ultrafiltration } \\
\text { device }\end{array}$ & 0.8 & 8 & $6-23$ & $\begin{array}{l}\text { first RO system hydraulic } \\
\text { solenoid valve }\end{array}$ & 0.7 & 7 \\
\hline $1-8$ & $\begin{array}{c}\text { primary RO membrane } \\
\text { module }\end{array}$ & 1.8 & 4 & $11-24$ & first tank & 0.3 & 4 \\
\hline $1-9$ & $\begin{array}{c}\text { secondary RO } \\
\text { membrane module }\end{array}$ & 1.8 & 4 & $6-25$ & $\begin{array}{l}\text { electromagnetic valve of } \\
\text { produced liquid level of } \\
\text { RO system }\end{array}$ & 0.7 & 7 \\
\hline $1-10$ & $\begin{array}{c}\text { CEDI heap of } \\
\text { membrane module }\end{array}$ & 2.4 & 10 & $6-26$ & $\begin{array}{l}\text { secondary RO high } \\
\text { pressure pump }\end{array}$ & 0.4 & 2 \\
\hline $1-11$ & electrical control system & 0.1 & 4 & $6-27$ & $\begin{array}{l}\text { Secondary RO system } \\
\text { into hydraulic solenoid } \\
\text { valve }\end{array}$ & 0.7 & 7 \\
\hline $1-12$ & $\begin{array}{c}\text { Primary conductivity } \\
\text { meter }\end{array}$ & 0.5 & 6 & $11-28$ & secondary tank & 0.3 & 4 \\
\hline $1-13$ & Primary level controller & 0.4 & 5 & $6-29$ & $\begin{array}{c}\text { Secondary RO system } \\
\text { hydraulic solenoid valve }\end{array}$ & 0.7 & 7 \\
\hline $1-14$ & $\begin{array}{l}\text { Secondary conductivity } \\
\text { mete }\end{array}$ & 0.5 & 6 & $6-30$ & $\begin{array}{l}\text { CEDI high pressure } \\
\text { water pump }\end{array}$ & 0.4 & 2 \\
\hline $1-15$ & $\begin{array}{c}\text { secondary level } \\
\text { controller }\end{array}$ & 0.4 & 5 & $6-31$ & CEDI solenoid valve & 0.7 & 7 \\
\hline $1-16$ & $\begin{array}{l}\text { resistance meter CEDI } \\
\text { water production rate }\end{array}$ & 0.6 & 5 & $11-32$ & CEDI water tank & 0.1 & 3 \\
\hline
\end{tabular}

Table 2 Reliability analysis results of CEDI system

\begin{tabular}{|c|c|}
\hline system reliability characteristic & the numerical \\
\hline failure rate $/ \mathrm{a}^{-1}$ & 68.3 \\
\hline repair rate $/ \mathrm{a}^{-1}$ & 5124.7 \\
\hline mean free error time/h & 240.64 \\
\hline mean time to repair $/ \mathrm{h}$ & 3.86 \\
\hline average life-span $/ \mathrm{h}$ & 286.42 \\
\hline mean probability of working & 0.9867413526 \\
\hline mean probability of no working & 0.0132586474 \\
\hline
\end{tabular}

As shown in table2, CEDI water treatment system under the condition of continuous work, system failure rate is $68.3 \mathrm{a}^{-1}$, the system mean free error time is $240.64 \mathrm{~h}$, about 10.0 days. Calculated on everyday 8 hours and system status does not change during downtime, system failure rate is $22.77 \mathrm{a}^{-1}$, the system mean free error time about 30 days, comparing the results conform to the CEDI system operation maintenance experience.

The analysis of system component importance.

In the CEDI water treatment system, the failure rate of one unit is increased 5 times while maintaining the failure rates of other units, the failure rate of each unit changes on the influence of the system mean free error time can be obtained [9], as shown in table 3. 
Table 3 Component importance analysis of CEDI system

\begin{tabular}{|c|c|}
\hline unit name & mean-time-to double failure/h \\
\hline disc filter & 187.84 \\
\hline precision filter & 153.62 \\
\hline fiber ultrafiltration device & 114.81 \\
\hline RO membrane & 102.43 \\
\hline water pump & 240.31 \\
\hline solenoid valve & 214.38 \\
\hline water tank & 236.94 \\
\hline CEDI unit & 187.25 \\
\hline
\end{tabular}

As shown in table 3, RO membrane, fiber ultrafiltration device and other components reduce system mean free error time greatly. Therefore, on the basis of improving the quality of the original water, reducing the RO membrane components such as failure rate will significantly improve the operation reliability of CEDI system.

\section{Conclusion}

GO methodology was applied to CEDI system reliability analysis, important indicators for the system reliability are obtained. And parameters of the reliability of the system components are further changed. Analysis the importance degree of each important part to improve the performance of these components are effective measures to enhance the reliability of CEDI water treatment systems. In this paper, the research shows that the GO methodology is applicable and can be spread and applied to work reliability and safety analysis of other water treatment equipment.

\section{References}

[1] Shen Zupei, Huang Xiangrui. Principle and application of the GO methodology [M].Beijing: Tsinghua university press,2004:27-33.

[2] Yang Wenshi, Wang Wei, Mi Guojiang. The GO methodology in anhydrous solid-state laser system reliability analysis [J].Infrared and Laser Engineering, 2010, 40(5): 479-483.

[3] Wang Fang. Electrodeionization water purification technology [J].Membrane Science and Technology, 2001, 21 (2) : 50-54.

[4] Li Zhijun, Xia Zhongmin, Zhou Boqing,et al. A study of mechanism of continuous demineralization using EDI technology[J]. Industrial water \&wastewater, 2004, 35 (4) : 39-41.

[5] Wang Zhi, Bao Chengyu. Application of GO methodology for reliability of YAG laser system [J]. Journal of Tsinghua university :Sci \& Tech, 2007,47 (3) : 377-380

[6] Cao Lu, Huang Huiqun, Zhang Chengyi. Reverse osmosis membrane pollution [J]. Chemical cleaning world, 2004, 22 (8) : 9-13.

[7] Li Hongshuang, Lu Zhenzhou. A practical and reliable numerical method for predicting the safe fatigue life of complex structure system [J]. Journal of northwestern polytechnical university, 2005, 23 (4) : 435-439.

[8] Shen Peizu, Huang Xianghui, Gao Jia. Application of GO methodology for reliability analysis of repairable system [J]. Nuclear Power Engineering, 2000, 21 (5) : 456-461.

[9] Wang Shujuan, Wang Guili, Zhi Guofu. Application and research of GO methodology in reliability analysis of synthetical simulated experiment system of railway electronic antiskid devices [J].System Engineering-Theory \& Practice, 2006, 10 (10) : 95-101. 